202 Thomas A. Layden et al.: Action of Nicotinamide Adenine Dinucleotide

Rappaport, M.: NAD effects on the biochemistry and psychological performance of alcoholics under ethanol stress. Quart. J. Stud. Alcohol 30, 570-584 (1969).

Utonishi, I. : Pharmacological actions of diphosphopyridine nucleotide I. Effects on peripheral vessels, heart beating and blood pressure. J. Vitaminol. 4, 30-36 (1958a).

- Pharmacological actions of diphosphopyridine nucleotide II. Effects on uterus, intestines and bladder, and on histological changes of various organs, J. Vitaminol. 4, 37-45 (1958b).

Thomas A. Layden

Schick Pharmaceutical, Inc.

12001 Ambaum Blvd., S.W.

Seattle, Washington 98146, U.S.A.

\title{
Erratum
}

\section{Behavioral Effects of Arecoline in Rats}

\section{S. N. Pradhan and S. N. DUTTA}

Psychopharmacologia (Berl.) 17, 49-58 (1970)

In Fig.4, Page 55, symbols for response and reinforcement should be reversed, that is, $\square$ should represent Reinforcement and $=$ Response. 